\begin{tabular}{lllll}
\hline Estudios de Economía Aplicada & Vol. 35-1 2017 & Págs. 7-34 \\
\hline
\end{tabular}

\title{
La fortaleza competitiva de la economía española
}

\section{M. ${ }^{\text {a }}$ Elisa ÁlVAREZ LóPEZ ${ }^{\text {a }}$ Josefa Vega CRESPo ${ }^{\text {a }}$}

a Universidad de Valladolid, Facultad de Ciencias Económicas y Empresariales, Avda. del Valle del Esgueva, 6, Valladolid,España.E-mail: elsa@eco.uva.es; josefa@eco.uva.es

\section{RESUMEN}

En este trabajo se repasan las características más destacadas de la paulatina inserción de las empresas españolas en los mercados exteriores y sus principales razones explicativas; un proceso que cuenta con una dilatada historia y que refleja la existencia de un sistema productivo sólido, que ha sido capaz de desenvolverse con relativo éxito en un contexto de creciente presión competitiva. Este examen de la trayectoria expansiva dibujada por las exportaciones españolas permite poner de relieve su fortaleza competitiva, pero también los retos que ha de afrontar si se quiere que continúen siendo la garantía de un crecimiento económico sostenido, sin incurrir en desequilibrios exteriores.

Palabras clave: Competitividad, España, exportaciones, cuota exportadora.

\section{The Competitive Strength of the Spanish Economy}

\begin{abstract}
In this paper we review the most important features of the progressive internationalization of Spanish firms and its main explanatory factors. This long process reflects the existence of a solid productive fabric which has been able to successfully develop in a context of increasing competitive pressure. The analysis of Spanish exports trajectory enables us to highlight their competitive strength as well as the new challenges that will have to be overcome in order to ensure a sustained economic growth.
\end{abstract}

Keywords: Competitiveness, Spain, Exports, Export Share.

Clasificación JEL: F10, F14

Artículo disponible en versión electrónica en la página www.revista-eea.net, ref. ə-35111 


\section{INTRODUCCIÓN}

Frente al repetido diagnóstico de la debilidad del tejido productivo español desde nuestra incorporación a la Unión Económica y Monetaria y la necesidad de mejorar nuestra competitividad, que se ha convertido en un objetivo prioritario de la política económica durante la reciente crisis, al igual que en un buen número de países de la zona euro, la positiva evolución de las exportaciones españolas -expresión de la capacidad productiva- revela la existencia de un sistema productivo sólido que ha sido capaz de desenvolverse con relativo éxito en un escenario de creciente presión competitiva, gracias a la firme estrategia de orientación hacia los mercados exteriores puesta en marcha por las empresas españolas ya hace muchos años, y en especial desde nuestra incorporación a la Europa comunitaria.

Precisamente, el propósito fundamental de las páginas que siguen es revisar los rasgos más destacados del paulatino afianzamiento de la exportación española y sus principales razones explicativas, prestando atención a su estructura por productos y mercados de destino, así como a las características de las empresas internacionalizadas. Esta mirada al comportamiento mostrado por el sector exportador español, a un tiempo que resaltar sus logros, permitirá poner de relieve los retos que ha de afrontar si se pretende que continúe siendo el soporte de un crecimiento económico sostenido, capaz de corregir el elevado desempleo existente, y libre de desequilibrios exteriores de importancia.

\section{EL AVANCE DE LAS EXPORTACIONES ESPAÑOLAS}

En el transcurso de la crisis que estamos tratando de dejar atrás, las exportaciones españolas han mostrado un elevado dinamismo, actuando como único soporte de la actividad económica y motor de la recuperación -esta vez sin devaluación ${ }^{1}$ - iniciada en la segunda mitad de 2013. En concreto, después del colapso del comercio mundial en 2009, anotan tasas de crecimiento por encima del 4 por 100, medidas en términos reales (Figura 1), de forma que su peso en el PIB ha alcanzado cotas históricas, pasando del 23,3 por 100 en 2009 al 32,7 por 100 en 2016, cifra que, respecto a nuestros socios europeos comparables en tamaño, únicamente es inferior a la de Alemania. Es más, los últimos datos disponibles en el momento de redactar estas páginas, relativos al primer semestre de 2016 (OMC, 2016), revelan que, entre los principales exportadores mundiales

\footnotetext{
${ }^{1}$ Su papel también fue clave en la recuperación de la crisis vivida por la economía española en los primeros años noventa, pero entonces encontraron un impulso fundamental en las tres devaluaciones consecutivas de la peseta que tuvieron lugar entre 1992 y 1993.
} 
y en un contexto de débil crecimiento de las corrientes comerciales ${ }^{2}$, tan solo cuatro países, encabezados por España, han aumentado sus ventas exteriores.

Figura 1

Evolución de las exportaciones españolas, 1996-2016

(tasa anuales de variación a precios constantes)

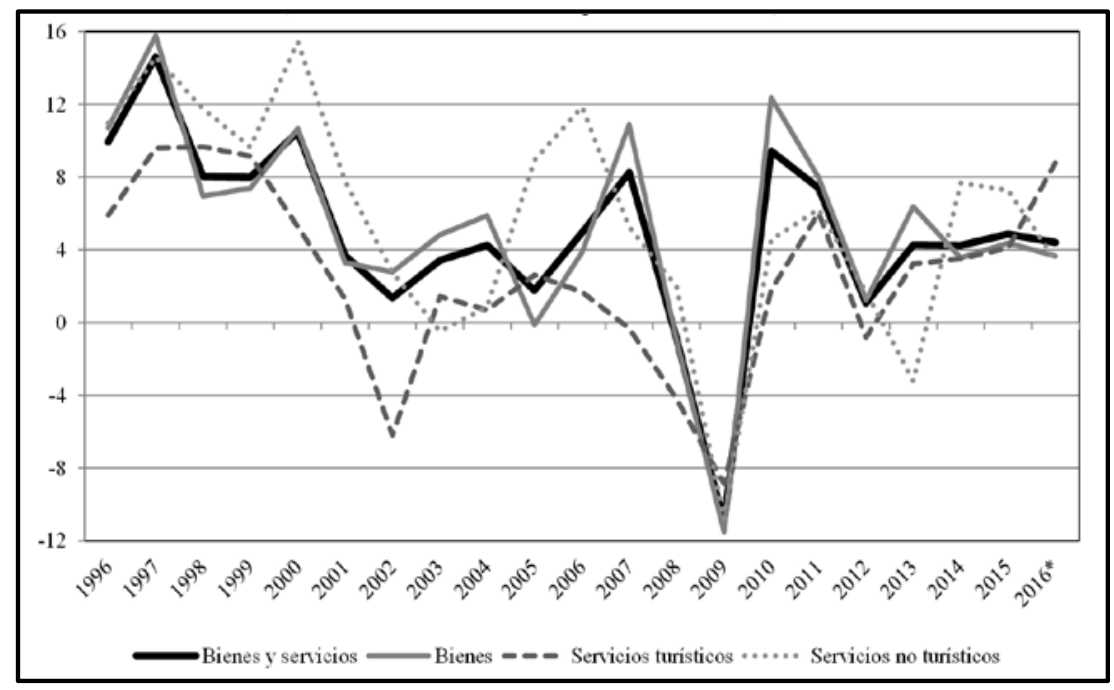

Nota: $\left(^{*}\right)$ Hasta el tercer trimestre.

Fuente: INE, Contabilidad Nacional de España.

Este vigor de la oferta exterior española desde 2010 resulta también notable en el escenario de la Unión Europea, no en vano, en términos reales, se sitúa prácticamente al mismo nivel que el incremento medio logrado por la de Alemania, tercera potencia exportadora global, y supera a la del conjunto de países comunitarios más desarrollados (UE-15). Destacable trayectoria que se prolonga durante los tres primeros trimestres de 2016, en los que se obtienen aún mejores resultados comparativos, sobrepasando las exportaciones españolas el crecimiento de las ventas exteriores de todas las grandes potencias comerciales europeas, incluida Alemania.

\footnotetext{
${ }^{2}$ En la primera mitad de 2016 el comercio mundial se ha estancado, después de haber anotado un lento ritmo de crecimiento en los dos años anteriores (2,7 por 100 en 2015 y 2,8 por 100 en 2014). Esa atonía en los intercambios ha llevado a la OMC a rebajar sus previsiones comerciales para el conjunto de 2016, situando la nueva tasa en un 1,7 por 100, la más baja desde 2009 (Jääskelä y Mathews, 2015; Gros, 2016a); un cifra que, de confirmarse, dejaría la ratio entre el avance del comercio y el de la producción (estimado en un 2,2 por 100) por debajo de uno, algo que no había ocurrido desde hace tres lustros. Para 2017, los últimos pronósticos apuntan a que, tanto los flujos comerciales (con un ascenso de entre el 1,8 y el 3,1 por 100), como el PIB mundial (2,5 por 100), se mantendrán en una línea de crecimiento moderado.
} 
Por otro lado, aun cuando el avance de las exportaciones ha sido impulsado por las de bienes, que suponen el 70 por 100 del total y han registrado notables ascensos, cercanos al 5 por 100 anual, son las ventas de servicios no turísticos las que han crecido a un ritmo más rápido (en especial, los servicios empresariales y los informáticos ${ }^{3}$ ), aventajando en volumen a las de turismo (en 2015 representan el 60 del total), lo que barre la todavía extendida imagen de España como un país que solo exporta servicios turísticos ${ }^{4}$.

Por lo demás, el gran dinamismo mostrado por las ventas exteriores se ha traducido en una notable contribución al crecimiento del PIB, cifrada en 1,4 puntos porcentuales como media desde 2010 y en su mayor parte (80 por 100) proveniente de las transacciones de bienes.

Pese a haber sido calificada por algunos como un "milagro" (Eppinger et al., 2015), la pujanza de las exportaciones españolas durante la etapa recesiva no es un fenómeno nuevo ni sorprendente, ni tampoco encuentra uno de sus principales estímulos en la necesidad de dirigir las ventas al exterior ante la atonía del mercado interno ${ }^{5}$, sino que es fruto de una firme apuesta de las empresas españolas por la internacionalización, liderada por las de mayor dimensión, que cuenta ya con una dilatada historia ${ }^{6}$.

En la vertiente de la exportación, este proceso se ve espoleado con la adhesión de España al proyecto comunitario, que obliga a nuestras empresas, ante la apertura total del mercado nacional a la competencia de las del resto de países socios, a buscar mercados exteriores a fin de sostener sus niveles de producción y, con ello, acometer una honda transformación de sus productos y métodos productivos. En estos primeros años de integración, las ventas dirigidas a la Europa comunitaria experimentaron un considerable ascenso, lo que, en el caso de las bienes, elevó su peso hasta algo más del 70 por 100 del total. Con todo, es

\footnotetext{
${ }^{3}$ Sobre la evolución de las exportaciones de servicios por categorías en el transcurso de la crisis, véase Peña Peña (2016).

${ }^{4}$ La oferta exterior de servicios no turísticos ha crecido de manera sostenida desde 2008, consolidándose como una importante fuente de ingresos, añadida al turismo, con la que financiar el déficit comercial. Su progresión durante estos años las convierte en uno de los cambios estructurales más significativos experimentados por la economía española a lo largo de la última década (Fuentes Castro, 2016).

${ }^{5}$ Si bien distintos estudios aportan evidencia de la existencia de una relación negativa entre la debilidad de la demanda interna y la evolución de las exportaciones para distintos países de la zona euro, entre ellos España (Belke et al., 2014 y 2015; Esteves y Prades, 2016), de acuerdo con las estimaciones efectuadas por Prades y García (2015), la caída de la demanda doméstica a lo largo de la crisis, y más en concreto la sufrida por el consumo privado, ha contribuido de forma positiva, pero moderada, al crecimiento de las exportaciones españolas de bienes entre 2009 y 2013.

${ }^{6}$ Un repaso de la larga trayectoria expansiva seguida por la oferta exterior española desde sus inicios en la década de 1960 puede encontrarse en Myro (2015a).
} 
en el decenio de 1990 cuando se cosechan los ritmos de expansión de las exportaciones más altos (10 por 100 de media anual en términos reales, 11 por 100 las de bienes; cifras que doblan las registradas en la década anterior y que superan claramente las alcanzadas por Francia, Italia o Reino Unido ${ }^{7}$ ). A lo largo de esta década, y siguiendo el camino marcado por las grandes empresas en los años ochenta, se amplía notablemente el número de firmas de menos 200 trabajadores que dan el salto al exterior (su porcentaje casi se duplica, destacando el colectivo por debajo de los 100 trabajadores), al tiempo que mejora la propensión a exportar en ambos segmentos de empresas, particularmente las de mayor dimensión, en las que el porcentaje de producción enviado al exterior pasa del 20 al 35 por 100, mientras que en las de menos de 200 trabajadores lo hace del 20 al 25 por 100, un umbral que parece resultar decisivo (Myro, 2015a) ${ }^{8}$, con significativos incrementos en los sectores que hoy son claves en la exportación, salvo alimentos, bebidas y tabaco, que adolece de una exigua vocación exportadora $^{9}$ (Álvarez y Vega, 2012).

Con el cambio de siglo, y durante los años de bonanza económica, en un escenario de intensificación de la competencia derivada de la irrupción de las economías emergentes en los flujos de comercio internacional, y con un tipo de cambio del euro en fuerte y continua alza $^{10}$, la trayectoria expansiva de las exportaciones no se interrumpe, aunque los registros se moderan, tanto en lo que se refiere al progreso de la base empresarial exportadora ${ }^{11}$, como al incremento del volumen de las ventas exteriores, que no obstante continua siendo apreciable (tasa media anual del 4,3 por 100; un punto por encima de la correspondiente al PIB). Este crecimiento sigue dependiendo fundamentalmente de los mercados comunitarios (Jiménez y Martín, 2010; Álvarez y Vega, 2012), pero también se ve favorecido por el notorio ascenso de los envíos hacia un buen número de los

${ }^{7}$ Para más detalle puede verse Myro et al. (2013).

${ }^{8}$ Conforme a los resultados ofrecidos en Merino de Lucas (2012), relativos a las empresas manufactureras españolas, la intensidad exportadora condiciona la consecución de ganancias de productividad, de forma que a partir de ese valor del 25 por 100 no se observan diferencias significativas en el ritmo de avance de la productividad entre las empresas y las multinacionales, pero sí respecto a las que exportan por debajo de ese nivel o no lo hacen.

${ }^{9}$ Dada la entidad de esta industria en el patrón exportador (cerca del 10 por 100 de las ventas totales de productos), su reducida intensidad exportadora condiciona la ratio agregada y da razón a aquellos que apuntan la estructura productiva española como un determinante esencial de la apertura al exterior, pues esta industria, y en menor medida el resto de las de bajo contenido tecnológico, suelen ser menos proclives a orientar su producción al resto del mundo (BarbaNavaretti et al., 2011).

${ }^{10}$ Entre 2000 y 2007, el euro incrementa su valor respecto al dólar en un 52 por 100.

${ }^{11}$ Desde 2000, y hasta el inicio de la crisis, únicamente se observa un aumento apreciable del número de empresas industriales que exportan en el tramo de tamaño entre 21 y 50 trabajadores (Myro et al., 2013). 
países ubicados a la cabeza de la expansión de las importaciones a escala global ${ }^{12}$. Con todo, el escaso grado de penetración en estos destinos más dinámicos, así como en otros más maduros y exigentes como los de Estados Unidos, Japón o Canadá, impidió un mayor aumento de las exportaciones, que aun así superó el logrado en Francia o Italia, pero sin alcanzar al de Alemania, mejor posicionada en ellos.

Precisamente, es en el hecho de que las empresas españolas no hayan sabido aprovechar el elevado potencial de estos mercados emergentes -algo que sí han conseguido desde 2010 y hasta 2013, cuando dan las primeras muestras de desaceleración-, donde hay que buscar la razón principal de la moderación en el avance exportador, y no en un problema de deterioro de la competitividad, como han querido ver algunos analistas, vinculando esta variable a la evolución de los costes y precios relativos ${ }^{13}$ (Banco de España, 2011). Una explicación que encuentra apoyo en el buen comportamiento relativo de la cuota exportadora de España, pese a la adversa evolución de los precios y costes de producción en relación a las economías industrializadas ${ }^{14}$, lo que fue bautizado como la paradoja o el puzle de los costes y la competitividad, o de la productividad y la competitividad exterior española (Myro, 2009) ${ }^{15}$. Así, considerando solo los

${ }^{12}$ Cabe destacar los casos de Rusia, China, Argelia, Turquía, Brasil y Marruecos, por tratarse de destinos que absorben un porcentaje de nuestras ventas superior al 1 por 100 (Álvarez y Vega, 2012), y para los que la Administración española ha puesto en marcha planes específicos de internacionalización (Planes Integrales de Desarrollo de Mercado), lo que viene a avalar la idoneidad de las políticas comerciales enfocadas a dispersar el patrón espacial del comercio exterior. En este mismo sentido, los resultados presentados en Vega y Álvarez (2011), obtenidos al aplicar la denominada metodología de la cuota de mercado constante (Richardson, 1971) a la trayectoria dibujada por la oferta exterior española entre 2000 y 2009, demuestran la positiva, aunque limitada, influencia que han tenido los mercados de Marruecos, Argelia y Turquía.

${ }^{13}$ Tradicionalmente, como indicadores de la competitividad de una economía se han utilizado los precios de sus productos (índices generales de precios o precios de exportación) o los costes de producción (a menudo los costes laborales unitarios, determinantes esenciales de los precios) comparados con los de los países con los que compite en los mercados internacionales, expresados en una moneda común; y ello porque muestran las ventajas de costes de las que disponen las empresas de un país frente a sus rivales de otros países a la hora de conquistar posiciones en el mercado.

${ }^{14}$ Sobre el retroceso de la competitividad en precios de la economía española desde su entrada en la Unión Económica y Monetaria, ampliamente documentado, pueden verse, entre otros, Pérez (2004), Gordo (2007), Canals y Fernández (2008), Doménech (2009), Martínez-Mongay y Maza Sierra (2009) y Banco de España (2011).

${ }^{15}$ En cualquier caso, como destacan Bajo-Rubio et al. (2016), no cabe calificar de sorprendente esta aparente contradicción entre la trayectoria de las ventas exteriores y los costes laborales unitarios, dado que hace casi cuarenta años Kaldor (1978) encontró, para una muestra de doce países industrializados y el periodo 1963-1975, que aquellos que habían logrado mayores ganancias de cuota de mercado eran también los que habían registrado mayores alzas en sus costes laborales unitarios, y viceversa, resultado conocido como la paradoja de Kaldor. 
productos industriales, en la etapa inmediatamente anterior a la crisis, los costes laborales unitarios crecieron más deprisa en España que en los principales países desarrollados, de forma que acumuló una considerable pérdida de competitividad en costes ${ }^{16}$; sin embargo, con la salvedad de Alemania, acusó en menor medida que ellos la escalada de las economías emergentes, con China a la cabeza, en las corrientes de comercio internacional, defendiendo su posición en la oferta mundial, mientras el resto de grandes países europeos -excepción hecha de Alemania-, Estados Unidos y Japón registraron una merma de entre un 20 y un 35 por 100 en su cuota exportadora (Figura 2) ${ }^{17}$.

Por otra parte, el alza en los costes españoles no fue óbice para que las empresas acrecentaran sus márgenes ${ }^{18}$; así, el avance de los márgenes empresariales se acentuó desde 1999 -en contra de lo que cabía esperar dado el escenario de más viva competencia que conllevaba la adopción del euro-, desempeñando un papel determinante en la elevación de los precios de los productos españoles (Estrada, Malo de Molina y Jimeno, 2009), lo que dista de evidenciar que las empresas percibieran que estaban perdiendo competitividad; al mismo tiempo, impide descartar que las subidas de precios no fueran el reflejo de mejoras en la calidad, variedad y singularidad de los productos que, al reducir la sensibilidad de la demanda al precio, habrían permitido que ni las ventas ni la rentabilidad ${ }^{19}$ de las empresas acusaran de forma notable su encarecimiento (Myro et al., 2013; Gros, 2016b).

${ }^{16}$ Fruto de un ascenso de los salarios mucho más rápido que el de la productividad del trabajo, entre 2000 y 2007, los costes laborales por unidad producida crecieron en la industria española a una tasa anual media del 2,7 por 100, mientras que se estacaron en la zona euro, subieron un 0,2 por 100 en Francia y en Alemania se redujeron un 1,6 por 100, lo que se tradujo en un deterioro de la competitividad del 20, 18 y 34 por 100 respecto a la eurozona, Francia y Alemania, respectivamente (Myro, 2014a). Asimismo, la pérdida de competitividad en términos de costes laborales unitarios se cifra en un 20 por 100 si la comparación se amplía a un conjunto de 36 países industrializados (Correa-López y Doménech, 2012).

${ }^{17}$ En el ámbito de los servicios, la trayectoria ha sido aún más positiva, pues el peso relativo de España, que tradicionalmente casi ha duplicado al que posee en los intercambios mundiales de productos, aumentó ligeramente hasta 2007. De nuevo aquí, España sobresale con respecto a la mayoría de sus socios europeos (si bien es superada por Alemania y Finlandia, amén de por Irlanda, cuyo comportamiento es excepcional), además de Estados Unidos y Japón, de modo que tampoco en este caso su cuota se vio afectada hasta ese momento por el espectacular progreso de los flujos procedentes de países como India, Rusia y China (Myro y Álvarez, 2010). Desde 2008, y al igual que ocurre en el resto de grandes potencias europeas, la cuota cae, aunque se mantiene notablemente por encima de la correspondiente a los bienes.

${ }^{18}$ El aumento de los márgenes empresariales, más marcado en los bienes comercializables, también tuvo lugar en el área euro, pero en menor cuantía.

${ }^{19}$ En realidad, las empresas industriales españolas despuntaron entre las europeas por las altas cifras de rentabilidad anotadas en la etapa anterior a la crisis (Costa et al., 2015; Peltonen et al., 2008). 
Figura 2

Evolución de las cuotas de exportación de bienes, 2000-2016 (índices, 2000=100)

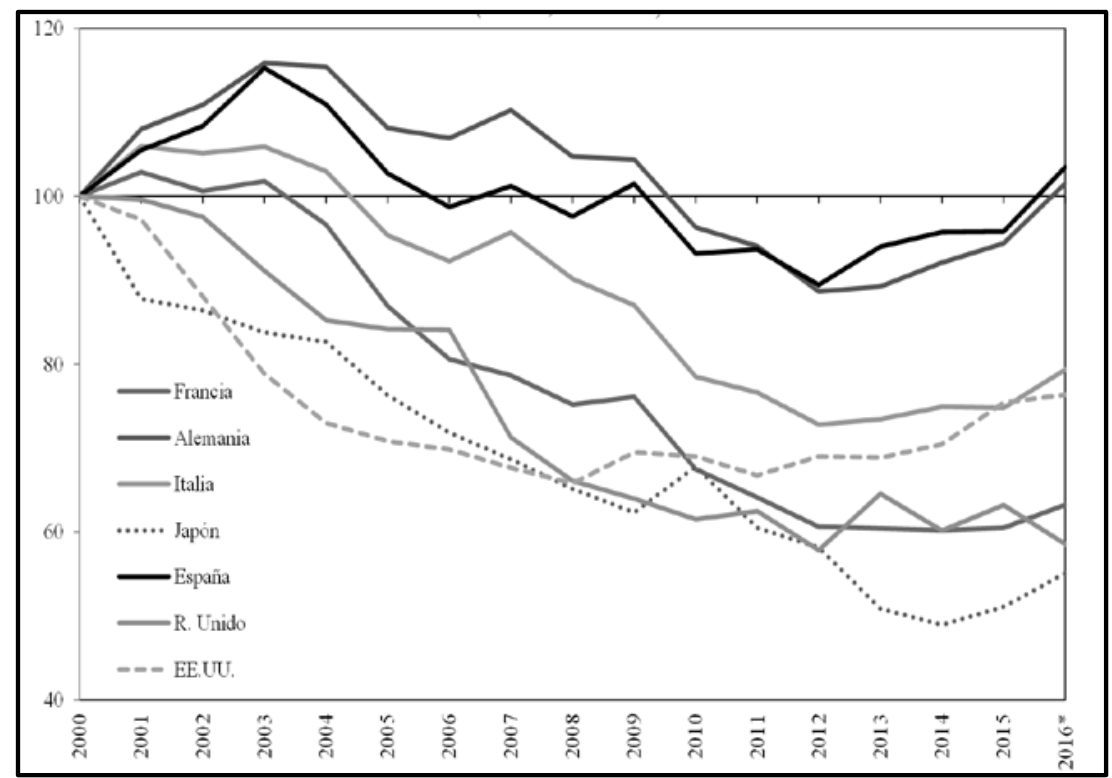

Nota: $\left({ }^{*}\right)$ Hasta el tercer trimestre.

Fuente: OMC.

Otra de las razones a menudo esgrimidas para dilucidar el simultáneo ascenso de los costes y las exportaciones españolas tiene que ver con la heterogeneidad de las empresas dentro de cada sector, un aspecto introducido en el trabajo seminal de Melitz (2003) -en el que se otorga a la productividad el protagonismo a la hora de explicar por qué unas empresas se involucran en la actividad exportadora mientras que otras permanecen volcadas al mercado interior ${ }^{20}-$, y que ha dado lugar a una fructífera línea de investigación en torno a los determinantes de los

${ }^{20}$ El nexo básico de unión entre la productividad y la actividad exportadora es que solo las empresas más eficientes (ex ante) pueden superar el umbral de rentabilidad requerido para afrontar los costes hundidos derivados de la entrada en los mercados exteriores y de sobrevivir a las presiones competitivas (lo que se conoce como el efecto selección en la exportación). Por lo demás, esta positiva asociación entre el nivel de productividad de las empresas y su inserción en las corrientes de comercio internacional aparece sobradamente confirmada por la evidencia empírica. Un buen resumen de la literatura disponible sobre este tema se ofrece en Behrens y Ottaviano (2011). 
flujos de comercio internacional ${ }^{21}$. El argumento es que el comportamiento de la productividad y los costes del conjunto de la industria no se ajusta al mostrado por el colectivo de empresas exportadoras, integrado por las de mayor dimensión y niveles de eficiencia y productividad más elevados, de forma que la pérdida de competitividad que reflejan las medidas generales de costes y precios corresponde al grupo de empresas orientadas al mercado doméstico, y podría justificar la debilidad del crecimiento del producto industrial en España respecto a los socios comunitarios más desarrollados ${ }^{22}$. La evidencia ofrecida por Antràs (2010), de acuerdo con la cual las firmas españolas de más de 50 trabajadores son tan productivas o más que las alemanas, británicas o estadounidenses, confrontación que resulta particularmente favorable en el tramo de más de 250 trabajadores donde se concentra la oferta exterior, efectivamente circunscribiría los problemas de productividad en términos comparados al segmento de empresas de reducida dimensión, que en España representan un porcentaje más destacado. Pero esta explicación por sí sola no es suficiente, porque las empresas exportadoras también registraron aumentos en sus costes laborales unitarios, en especial las medianas y pequeñas, y ni siquiera las grandes exportadoras lograron notables ganancias de productividad, con lo que asimismo vieron deteriorada su competitividad en precios respecto a sus rivales europeas, si bien en menor medida que el agregado de la industria, perdiendo parte de la ventaja en productividad y costes adquirida a lo largo del decenio de 1990 (Myro, 2014a) ${ }^{23}$.

En definitiva, el hecho de que el avance de las exportaciones españolas durante la última etapa expansiva no haya descansado en una favorable trayectoria de los precios y costes relativos no implica que esta no incida en la capacidad de una economía para mejorar su posición en el mercado internacional, sino que otros factores -a los que enseguida se hará referenciahan jugado un papel más relevante en el dinamismo mostrado por nuestra oferta

${ }^{21}$ Desde comienzos de la pasada década, la disponibilidad de datos de empresas relativos a su tamaño, productividad, organización, esfuerzo innovador e intensidad exportadora, entre otras características, ha permitido incorporar la heterogeneidad empresarial en los modelos de comercio internacional y, con ello, avanzar en la identificación de los determinantes de la estructura del comercio exterior. Un repaso del creciente número de aportaciones en este campo puede consultarse, por ejemplo, en Bernard et al. (2012), Melitz y Redding (2014) y Wagner (2016).

${ }^{22}$ Un análisis del crecimiento de la producción industrial española en relación con los países de su entorno puede encontrarse en Gandoy y Álvarez (2015).

${ }^{23}$ En el periodo 2002-2007, las empresas exportadoras de más de 200 trabajadores, responsables del 70 por 100 de las ventas exteriores, incrementaron su productividad a un ritmo anual del 1,15 por 100 , frente al 0,90 por 100 del conjunto de la industria, en tanto que sus costes laborales unitarios crecieron sensiblemente por debajo de la media del sector (alrededor de un punto porcentual menos). En paralelo, la productividad ascendió a una tasa del 2,6 por 100 en la zona euro, 3,4 por 100 en Alemania y 3,3 por 100 en Francia, mientras que los costes laborales unitarios se estancaron o redujeron. 
exterior, compensando la evolución al alza de los costes; y, en consecuencia, que el análisis de la competitividad no puede limitarse a las tradicionales medidas generales de precios y costes relativos, puesto que ello supone dejar fuera de la valoración otros elementos que condicionan la fortaleza exportadora de un país, como son la calidad y variedad de los productos ofertados, su adecuación a los requerimientos de la demanda mundial, el dinamismo de los mercados a los que se dirigen, el grado de orientación de sus empresas hacia los mercados exteriores o la participación de estas en cadenas globales de valor. Una afirmación que, por lo demás, respaldan el cada vez mayor número de estudios que demuestran la baja correlación existente entre los indicadores de competitividad basados en precios y costes relativos y la evolución de las exportaciones (Allard et al., 2005; Crespo Rodríguez, et al., 2011; Giordano y Zollino, 2015), de la cuota exportadora (Correa-López y Doménech, 2012) o del saldo comercial (Bajo-Rubio et al., 2016).

Las dificultades que entraña la medición de la competitividad tienen que ver con la propia ambigüedad del concepto cuando se aplica en el ámbito macroeconómico. Desde esta perspectiva, no existe una definición consensuada ni precisa de la competitividad, asociándose en muchos casos con la capacidad de crecimiento o de creación de empleo de una economía (European Commission, 2000; OECD,1992), o incluyendo en su valoración una amplia gama de factores (macroeconómicos, microeconómicos, institucionales...) que condicionan las inversiones en capital físico, humano y tecnológico y, por ende, el avance de la productividad, como es el caso del Índice de Competitividad Global elaborado por el Foro Económico Mundial ${ }^{24}$. Pero la competitividad, entendida como la capacidad de una economía para vender su producción en el exterior, en realidad está haciendo referencia a las empresas, pues son estas las que rivalizan con las de otros países para comercializar sus productos en los distintos mercados, lo que explica que la evolución de los indicadores de precios y costes relativos referidos al conjunto de la economía, expresivos solo de algunos de los factores que impulsan las exportaciones, no siempre coincida con la mostrada por la cuota de esa economía en las exportaciones mundiales, un indicador fundamental de competitividad revelada (ex-post) ${ }^{25}$, o dicho de otra forma, de la capacidad de las

24 La última versión de este índice, calculado para 138 países, puede consultarse en https://www.weforum.org/reports/the-global-competitiveness-report-2016-2017-1.

${ }^{25}$ Otros indicadores de resultados manejados con frecuencia son los que recogen la evolución de las importaciones o del déficit en el comercio de bienes y servicios, pero su expansión, más que la manifestación de debilidades competitivas, suele ser sobre todo el reflejo de un excesivo aumento del gasto interno en relación a la oferta agregada. De hecho, y tal como señala Myro (2015b), en la etapa previa a la crisis, las importaciones españolas de bienes crecieron mucho, como consecuencia del marcado ascenso de la demanda nacional, si bien por debajo de lo previsible a tenor de los valores estimados de la elasticidad renta de nuestras compras exteriores, y ello a pesar del incremento de los costes laborales y la apreciación del euro. 
empresas de rivalizar con las de otros países, cuyo avance naturalmente depende de los costes y precios de los productos comparados con los de los contrincantes comerciales, pero también de su calidad y singularidad y su adaptación a la demanda mundial, amén de la diversificación de los mercados de destino y la intensidad exportadora de las empresas, como ya se ha indicado.

De este modo, el destacado crecimiento de las exportaciones españoles de bienes durante la crisis -solo comparable al de Alemania entre las principales economías desarrolladas-, que desde 2012 le ha permitido recuperar posiciones en la oferta mundial de bienes (Figura 2), situando su cuota en el 1,85 por 100, aun cuando se ha apoyado en el descenso de algunos segmentos de salarios ${ }^{26} \mathrm{y}$ de los costes laborales unitarios ("devaluación interna") ${ }^{27}$, acompañado de menores costes de acceso a la financiación, así como de la depreciación del euro hasta 2012, que vuelve a producirse en $2015^{28}$, no hubiese sido posible sin la trayectoria expansiva anterior, que cosecha sus mayores logros en el decenio de 1990, tal como se ha reseñado. Es también en esta década cuando las empresas españolas comienzan a explorar la otra vía, más compleja, de internacionalización, la implantación productiva en otros países a través de la inversión exterior, transitando por ella a un paso muy vivo desde los últimos años noventa y hasta el inicio de la crisis financiera ${ }^{29}$, gracias sobre todo al sobresaliente esfuerzo llevado a cabo por un conjunto de grandes compañías

${ }^{26}$ Entre 2011 y 2014 la retribución media de los asalariados españoles cayó un 1,5 por 100, aunque esta reducción únicamente ha afectado a los salarios mensuales inferiores a 2.173 euros (en particular los de menos de 655 euros que han bajado un 15 por 100, mientras que los comprendidos entre 1.837 y 2.173 euros solo lo han hecho un 0,1 por 100) (Martín, 2016).

${ }^{27}$ Merced al proceso interno de ajuste de costes y precios relativos que está teniendo lugar desde 2008, España ha conseguido revertir la práctica totalidad de la pérdida de competitividad en costes laborales unitarios acumulada frente a los países desarrollados entre 1999 y 2007, mientras que, en términos del IPC, solo se ha rectificado parcialmente el elevado diferencial acumulado frente a la eurozona (Gómez Loscos y Martín Machuca, 2014).

${ }^{28}$ En 2013 y 2014, el euro se apreció, lo que unido al templado crecimiento del comercio mundial limitó el avance de las ventas europeas. En este sentido, algunos estudios revelan que la repercusión de un aumento del valor de la moneda es más negativa que la derivada del alza de los costes labores unitarios (Breuer y Klose, 2015), posiblemente porque, a diferencia de esta última, su origen es externo a las empresas, de manera que difícilmente pueden anticiparla y trasladarla a los precios finales, lo que conlleva una rebaja de los márgenes obtenidos en la exportación.

${ }^{29}$ En el lapso de apenas una década (1998-2007), España deja de ser un país fundamentalmente receptor de inversiones extranjeras directas para pasar a ser también un emisor aventajado, acaparando, a la altura de 2007, el 3,2 por 100 de la inversión directa mundial, una cifra solo ligeramente inferior a la anotada por el stock de inversión recibida (3,4 por 100). El lector interesado puede acudir al libro de Myro (2014b) en el que se recoge un exhaustivo estudio, tanto de la inversión directa recibida por la economía española, como la efectuada por sus empresas en otros países, con el propósito de valorar de forma precisa su amplia gama de efectos y su potencial de desarrollo en los años venideros. 
encuadradas en las actividades de servicios (entre las que despuntan banca y seguros y telecomunicaciones) y energía, pero al que asimismo se han sumado empresas industriales pertenecientes a distintos sectores (metalurgia, productos de minerales no metálicos, química, automoción y alimentos). La intensidad de este proceso, que la crisis ha aminorado, pero en absoluto truncado, y que se ha reactivado en los dos últimos años ${ }^{30}$, ha convertido a España en un destacado inversor en el extranjero, lo que ha incidido positivamente, tanto sobre las principales magnitudes agregadas de la economía, como sobre la competitividad de las propias empresas inversoras (Myro, 2014b; Merino de Lucas, 2012).

Así pues, las empresas españolas, guiadas por el reducido núcleo de las de mayor dimensión, han probado su capacidad para sobrepasar el espacio más cercano del mercado doméstico y competir en el escenario internacional con buenos resultados, en un proceso secuencial que, en consonancia con el difundido modelo de la Escuela de Uppsala (Johanson y Vahlne, 1977; Johanson y Wiedersheim-Paul, 1975), les ha llevado, primero, a optar por estrategias de exportación que les han permitido adquirir el conocimiento y la experiencia necesarios para, posteriormente, acometer la creación de filiales productivas en el extranjero, dos modalidades de internacionalización que se retroalimentan ${ }^{31}$.

\section{LAS BASES DE LA COMPETITIVIDAD EXTERIOR ESPAÑOLA}

Aunque ya en el anterior apartado se ha hecho alusión a la combinación de factores que están detrás del paulatino afianzamiento de las empresas españolas en los mercados de exportación, procede ahora prestarles una mayor atención, a fin de poner de relieve los puntos fuertes del tejido productivo español $y$, con ello, obtener una idea más precisa de las potencialidades de expansión de nuestra economía, cuya materialización necesariamente pasa por la continuidad del avance en el proceso de internacionalización.

Pues bien, las claves explicativas de la fortaleza competitiva revelada por las exportaciones españolas, que han sido exploradas con detenimiento en los trabajos de Myro et al. (2013) y Myro (2015a), son las siguientes:

${ }^{30}$ Una evaluación del impacto de la reciente etapa recesiva y profunda crisis vivida por la economía española sobre el ascenso de la inversión directa en el exterior, su distribución por sectores y países, las rentabilidades alcanzadas y la evolución del número de empresas puede encontrarse en Álvarez López et al. (2016).

${ }^{31}$ De acuerdo con la evidencia aportada por Esteve y Rodríguez (2014) en torno al vínculo existente entre exportación e inversión exterior directa, la realización de la primera de estas actividades eleva en 9 puntos porcentuales la probabilidad de llevar a cabo la segunda, mientras que el hecho de que una empresa invierta en el exterior aumenta en 30 puntos porcentuales la probabilidad de exportar, resultados que son independientes del tamaño de la empresa considerado. 
- Una composición por productos de la oferta exterior crecientemente adaptada a los requerimientos de la demanda mundial. Así, salvo en el caso de los equipos de telecomunicaciones -que, al igual que ocurre con el resto de manufacturas TIC, disponen de un escaso relieve, en concordancia con un desarrollo industrial más débil en ellos, dependiente en gran medida del capital extranjero ${ }^{32}$-, en la estructura de nuestras exportaciones destacan los sectores que igualmente cuentan con mayor presencia en la oferta mundial: vehículos de motor, química, maquinaria y equipo mecánico y maquinaria eléctrica, entre los de contenido tecnológico medio-alto; metálicas básicas, entre los de medio-bajo, y productos agroalimentarios y textil y confección, entre las industrias tradicionales. Además, en los últimos tres lustros, han ganado peso los sectores que se han mostrado más dinámicos en el comercio internacional: productos farmacéuticos y medicamentos, metálicas básicas, maquinaria eléctrica, química, productos metálicos y alimentos, bebidas y tabaco. Del mismo modo lo han hecho textil y confección y otro material de transporte (Álvarez y Vega, 2016). Por tanto, España se ha beneficiado de un patrón de especialización en el que se combinan productos de alta, media y baja intensidad tecnológica y cada vez más acomodado a la orientación de la demanda mundial, situándose entre los países con una cesta exportadora más diversificada, tanto a escala mundial (Hidalgo y Hausmann, 2009), como con respecto al grupo de economías más desarrolladas de la Unión Europea (Gordo y Tello, 2011; Donoso y Martín, 2017), ámbito, este último, en el que aparece como el país que a lo largo de las dos últimas décadas ha anotado un mayor incremento en el número de mercancías que exporta con ventaja comparativa, como puede comprobarse en el trabajo recién citado de Donoso y Martín, en este mismo número de la revista.

De igual forma, la trayectoria de las exportaciones de servicios da buena prueba de la capacidad de diversificación del patrón productivo español, pues desde comienzos del presente siglo todas las partidas de servicios no turísticos, salvo los informáticos y los royalties, han ganado peso en el comercio mundial, siendo especialmente positivo el avance anotado por un segmento de servicios clave, los dirigidos a empresas, entre los que sobresalen por sus altas cuotas los

${ }^{32}$ Perjudicadas por el proceso de deslocalización de empresas multinacionales hacia los países del Centro y el Este de Europa y, en menor medida, de Asia (Myro y Fernández-Otheo, 2008; Álvarez y Vega, 2012), esta agrupación de actividades ha rebajado su ya escasa aportación al total de ventas de nuestro país, alejándola aún más de la que anotan en la demanda global, donde asimismo han visto mermada su participación. El hecho de que, al mismo tiempo, estos sectores hayan registrado aumentos notables en su propensión a exportar es únicamente indicativo de la reducción relativa de su tejido productivo, y remite a problemas fundamentalmente de índole tecnológica que impiden el desarrollo de una industria manufacturera de entidad en el segmento de las TIC en España. 
de asistencia jurídica, publicidad, arquitectura, ingeniería y servicios técnicos (Cuadrado Roura et al., 2015).

- Un notable nivel de calidad de los bienes exportados. Aunque no todas las aproximaciones a la cuantificación de la calidad basadas en los precios (procedimiento frecuentemente utilizado a la hora de abordar este análisis y que implica asumir que altos precios son indicativos de elevadas calidades), en particular las que utilizan los índices de valor unitario de las exportaciones, respaldan esta afirmación ${ }^{33}$, sí lo hacen muchas otras, como las realizadas a partir del cálculo de la elasticidad precio de la demanda exterior de los distintos productos, en las que España aparece como el país de la eurozona con los valores más bajos (Goldman Sachs, 2011), o del precio relativo de las exportaciones ajustado por la calidad (Benkovskis y Woerz, 2015), que apuntan a una mejora de la calidad de las ventas españolas durante la última década. También apoya la apreciable calidad de nuestros productos la información proporcionada, para el año 2008, por la encuesta European Firms in a Global Economy (EFIGE) ${ }^{34}$, conforme a la cual, con independencia del tramo de tamaño considerado, las empresas españolas superan la media europea en distintos indicadores: proporción de compañías con certificados de calidad, grado de calidad medio de sus productos y porcentaje de ellas que discriminan precios en los mercados en función de la calidad de los bienes ofertados en cada uno de ellos (Martín y Tello, 2013). A ello cabe añadir que, de acuerdo con el indicador propuesto por Hausmann et al. (2007), para valorar el nivel de sofisticación de las exportaciones de un país (término que encierra facetas como el contenido tecnológico del producto, su diseño, su diferenciación o el prestigio de la marca), prácticamente la mitad de la oferta exterior española se compone de productos de alta y media alta sofisticación (Álvarez y Vega, 2016), esto es, de bienes que precisan de las ventajas en la dotación factorial, tecnología y comportamiento individual de las economías con superior renta por habitante. Un resultado que, dentro del grupo de mediaalta sofisticación -al que corresponde el mayor peso comercial-, obedece en gran medida a las ventas encuadradas en la industria de vehículos de motor,

33 Así, Gordo y Tello (2011) encuentran que, respecto a las principales economías de la Unión Europea, España está posicionada en la exportación de segmentos de inferior calidad, sin que esta situación haya registrado modificaciones significativas en el curso del pasado decenio. En la misma línea, según los resultados ofrecidos por Alcalá (2013), relativos al año 2007, el nivel medio de calidad de los productos españoles es inferior al del conjunto de la zona euro, así como al de Alemania, Francia, Italia y Estados Unidos.

${ }^{34}$ Esta encuesta suministra información detallada sobre la calidad de la producción, y de distintas variables que influyen en la misma (como la dotación de capital humano y el grado de innovación), para una muestra de aproximadamente 15.000 empresas manufactureras de siete países de la Unión Europea: Austria, Alemania, Francia, Hungría, Italia, España y Reino Unido. Con todo, conviene advertir que deja fuera los establecimientos de menos de diez trabajadores, lo que entraña un sesgo de representación en favor de las firmas de mayor tamaño. 
pero al que también contribuyen las pertenecientes a otros sectores, con menor presencia relativa, pero asimismo claves, en nuestro patrón exportador: maquinaria y equipo mecánico, maquinaria eléctrica, productos farmacéuticos y medicamentos y química. Las dos últimas actividades mencionadas destacan además por el apreciable porcentaje que suponen los productos de alta sofisticación en sus envíos al exterior.

- Una cartera de destinos en la que se han combinado con acierto mercados maduros y emergentes. Pese al notorio proceso de diversificación registrado durante los tres últimos lustros hacia plazas fuera de la Unión Europea, el perfil geográfico de las exportaciones se mantiene claramente sesgado hacia nuestros socios europeos (absorben el 62,3 por 100 de las ventas de bienes, casi doce puntos porcentuales menos que en el año 2000), con Francia y Alemania como clientes preferentes, seguidos por Portugal, Italia y Reino Unido. Esta elevada dependencia del mercado comunitario, uno de los más maduros y con mayor capacidad de compra en la esfera internacional, lejos de suponer un freno, ha favorecido el avance de la participación de España en la oferta mundial desde comienzos del presente siglo, compensando la reducida cuota de penetración anotada -salvo en contados casos como los de Marruecos, Argelia o Turquía- en el grupo de países que durante este tiempo han liderado el ascenso de las importaciones a escala global y que, de acuerdo con las previsiones de distintas instituciones financieras y organismos internacionales, presidirán el crecimiento de la economía mundial en los próximos años -los denominados EAGLEs (“águilas” en español), en especial China e India-, o se configuran como potenciales candidatos para hacerlo: países Nest (“nido”) ${ }^{35}$. Pero en aras del progreso de las exportaciones españolas también ha actuado su progresiva orientación hacia un buen número de las economías que han manifestado una superior vocación importadora, como Marruecos, Turquía, China, Argelia, Brasil y Rusia, y a la que sin duda han coadyuvado los Planes Integrales de Desarrollo de Mercado puestos en marcha por la Secretaría de Estado de Comercio, principal responsable de la política de promoción

${ }^{35}$ En 2010 BBVA Research creó un grupo de economías emergentes llamadas EAGLEs (acrónimo en inglés de economías emergentes y líderes del crecimiento), cuya contribución individual al aumento estimado del PIB mundial en la siguiente década se espera que sea superior al de la media de las grandes economías desarrolladas (excluida la estadounidense por razones de tamaño). Este catálogo de economías clave se ha ido revisando cada año en función de la actualización de las previsiones de crecimiento, de modo que, en 2016, se compone de quince países, encabezados por China e India que explicarán, respectivamente, el 29 y 17 por 100 del crecimiento global entre 2015 y 2025. A ellos se une otra lista, la de los denominados países Nest, que podrían convertirse en EAGLEs si consiguen mejorar su comportamiento respecto a las previsiones actuales (BBVA, 2016). 
exterior en España ${ }^{36}$. Este proceso de implantación en nuevos territorios claramente expansivos, cuya positiva incidencia en el desarrollo de la capacidad exportadora de nuestro país ha sido puesta de relieve en un abundante número de estudios realizados desde diferentes enfoques ${ }^{37}$, se ha acelerado en los años de la crisis, de rápida expansión de las economías emergentes y de atonía de las comunitarias. En este sentido, los resultados presentados por De Lucio et al. (2017), que pueden verse en este monográfico, indican que, a lo largo del último quinquenio, la contribución de la diversificación de los mercados de destino al crecimiento de las exportaciones españolas ha superado la correspondiente a la ampliación de la base exportadora.

El gradual giro de los canales de comercialización hacia áreas no comunitarias ha sido general a las diferentes actividades industriales, pero ha cobrado especial intensidad en algunas como medicamentos o maquinaria y equipo mecánico (su porcentaje de ventas a la Unión Europea ha sufrido una merma, respectivamente, de casi 25 y 10 puntos). Cuando se calcula el impacto de la composición geográfica del comercio sobre la evolución de la cuota de exportación para cada uno de los sectores manufactureros (su efecto mercado ${ }^{38}$ ) se obtienen resultados positivos en la mitad de ellos, despuntando madera y corcho, otro material de transporte, muebles y vehículos de motor; además, en

${ }^{36}$ Entre sus actividades de promoción, la Secretaría de Estado de Comercio definió hace ya varios años un nuevo instrumento (que ha sido sancionado en el Plan Estratégico de Internacionalización de la Economía Española, 2014-2015): el Plan Integral de Desarrollo de Mercado (PIDM), con el fin de fortalecer la presencia de los productos y las empresas españolas en mercados estratégicos. Hasta el momento, y en el marco del acuerdo firmado en diciembre de 2004 entre el entonces Ministerio de Industria, Turismo y Comercio y la CEOE, se han llevado a la práctica los siguientes PIDM: Argelia, Australia, Brasil, China, Corea del Sur, Estados Unidos, Filipinas, India, Indonesia, Japón, Marruecos, México, Rusia, Singapur, Sudáfrica, Turquía y los países del Consejo de Cooperación para los Estados Árabes del Golfo: Arabia Saudí, Kuwait, Baréin, Qatar, Emiratos Árabes Unidos y Omán. Se trata de una gran parte de los países EAGLEs y alguno de los Nest como Argelia, Marruecos y Sudáfrica, en los que la posición española es más holgada. En el marco de estos PIDM, se acometen las actuaciones promocionales típicas: misiones comerciales, misiones de estudio, misiones inversas (las celebradas en España), planes de contacto con las administraciones del país objetivo, campañas de promoción, jornadas técnicas, ferias (a través de pabellones oficiales o de stands informativos), semanas gastronómicas y planes de empresa. A menudo, estas acciones son de carácter sectorial y con frecuencia se enmarcan en planes sectoriales más amplios (agroalimentario, general de alimentos, del aceite de oliva y la aceituna de mesa, del vino, de los azulejos, de internacionalización de la tecnología, de infraestructuras, del diseño español, de la moda, mobiliario de oficina, mueble de diseño, audiovisual...).

${ }^{37}$ Entre estos estudios cabe destacar, además de los ya mencionados de Jiménez y Martín (2010), Gordo y Tello (2011) y Vega y Álvarez (2011), los de Máñez et al. (2011), Martín (2011) y De Lucio et al. (2011, 2017).

${ }^{38}$ Siguiendo la metodología de la cuota de mercado constante, el denominado efecto de mercado recoge la ganancia o pérdida de cuota derivada de encaminar las ventas hacia los mercados cuya demanda ha sido más o menos dinámica. 
los que es negativo, no alcanza gran dimensión (Myro et al., 2013). Por consiguiente, al igual que para el agregado de la oferta exterior, cabe calificar de buena la combinación de viejos y nuevos mercados, lo que no significa que se hayan desaprovechado importantes oportunidades como consecuencia de la reducida presencia en las economías emergentes del grupo de los EAGLEs, así como en varias de las desarrolladas fuera del ámbito europeo, como Estados Unidos y Canadá. Por lo demás, el análisis de la relación entre el ritmo medio de variación de las exportaciones y el cambio registrado en su grado de concentración por países durante la primera década de este siglo muestra que una gran parte de las industrias en las que la distribución de sus ventas se ha hecho más diversificada coinciden con aquellas que han mantenido un comportamiento exportador más dinámico que la media, aspecto en el que sobresalen medicamentos y metálicas básicas, sectores clave en la exportación española, con clara fortaleza competitiva. En sentido contrario, la mayoría de las industrias en las que ha aumentado el nivel de concentración espacial de sus ventas se hallan entre las que han cosechado peores registros en términos de crecimiento de sus envíos al exterior, particularmente las relacionadas con las TIC. Unos resultados, en definitiva, que avalan la idea -ya evidenciada en numerosos trabajos ${ }^{39}$ - de que la diversificación de mercados constituye uno de los determinantes del éxito exportador de un país. Con todo, ello no debe llevar a descuidar las posiciones conquistadas en los territorios de sólida implantación. De hecho, los efectos positivos del acceso a nuevos destinos se ven amplificados cuando esta estrategia se compagina con otras dirigidas a profundizar en mercados de mucho éxito ${ }^{40}$.

- Un conjunto relativamente amplio de empresas exportadoras, de dimensión superior a 200 trabajadores $^{41}$, con elevada eficiencia comparada, no solo respecto al universo total de empresas, sino también en relación a sus competidoras de Alemania, Reino Unido y Estados Unidos, y en las que, con arreglo a la información proporcionada por el ICEX, se reúne el 70 por 100 de

\footnotetext{
${ }^{39}$ Véanse, entre otros, Easterly et al. (2009) e Hidalgo y Hausmann (2009).

40 En el estudio de Easterly et al. (2009) se demuestra que los países que más exportan acompañan la diversificación geográfica de sus ventas exteriores con una concentración de las mismas en un reducido número de productos y emplazamientos, que estos autores conceptúan como "grandes éxitos" (big hits).

${ }^{41}$ El Directorio Central de Empresas del INE (DIRCE) contabiliza cerca de 5.400 empresas con más de 200 trabajadores, de las cuales alrededor de 1.300 son manufactureras; dentro de estas últimas, 350 superan los 500 empleados.
} 
las ventas exteriores de bienes industriales ${ }^{42}$. A la cabeza de este grupo se encuentran las exportadoras superstars (en terminología de Freund y Pierola), el 1 por 100 de las firmas de mayor volumen exportador (en el ámbito de las manufacturas, su número ronda las 130, según los datos del DIRCE), responsables del 53 por 100 del total. A la par, si se atiende al análisis de los márgenes de crecimiento de las exportaciones españolas realizado por De Lucio et al. (2017), este núcleo de empresas concentra más de la mitad de variación registrada, tanto en el margen intensivo (valor de las relaciones comerciales que permanecen), como en el extensivo (número de empresas, destinos y productos) en el periodo 1997-2015, siendo especialmente intensa, dentro de este último, la contribución en el componente de entrada de empresas (algo más del 75 por 100).

Por otra parte, un significativo porcentaje de este distinguido colectivo de exportadoras son "multiproducto" y "multidestino" y cuentan con filiales en un amplio número de países, europeos y, sobre todo, latinoamericanos, a los que se dirigen buscando acrecentar su dimensión corporativa y conseguir altas rentabilidades. De hecho, las multinacionales españolas, que han acumulado habilidades tecnológicas y organizativas, simultanean su presencia en economías desarrolladas y en desarrollo, adquiriendo ventajas en las primeras y explotándolas en las segundas (Guillén y García Canal, 2011). Tampoco puede dejarse de señalar que entre estas grandes empresas exportadoras se ubican las filiales de las multinacionales extranjeras instaladas en España, a las que cabe atribuir la tercera parte de las exportaciones manufactureras, una proporción superior a la cuota que alcanzan en la producción (24,5 por 100), lo que denota que, frente a las empresas de capital nacional, las filiales extranjeras despuntan por su intensidad exportadora, una característica vinculada igualmente a su mayor tamaño (Álvarez y Fernández-Otheo, 2014).

Por tanto, como apuntan Marin, Schymik y Tscheke (2015), las "superestrellas” de la exportación españolas tienen más en común con las de otras economías avanzadas europeas de lo que sugiere el desarrollo macroeconómico de los países, algo en lo que influyen de manera decisiva no solo el tamaño de las

${ }^{42}$ La concentración de los flujos de comercio exterior en las firmas de mayor tamaño no es un rasgo exclusivo de España, sino que se repite en todos los países, y encuentra explicación, como ya se ha señalado, en el hecho de las grandes empresas anotan niveles de productividad más elevados y disponen de mayor capacidad para afrontar los costes fijos y variables que conlleva la actividad exportadora. En el trabajo de Freund y Pierola (2013), se obtiene, para una muestra de 32 países y los años 2004-2008, que el 5 por 100 de las empresas industriales de superior dimensión aglutinan casi el 80 por 100 de la oferta exterior de cada país. Más aún, tan solo el 1 por 100 de las firmas más exportadoras, a las que se alude con el nombre de superstars, acumulan el 53 por 100 del total. Por otra parte, la concentración de los flujos de exportación también se observa en España en las actividades de servicios, si bien en este caso las diferencias en el tamaño entre empresas exportadoras y no exportadoras no es tan acusada (Minondo, 2012; Cuadrado Roura et al., 2015). 
mismas, sino también la elección organizativa y la calidad de la gestión directiva $^{43}$. El análisis realizado por estos autores demuestra que las grandes exportadoras españolas basan su estrategia competitiva en la mejora de la calidad de los productos, obtenida a través de la combinación de una gestión descentralizada $^{44}$ (con menos niveles jerárquicos) que incentiva a los trabajadores a generar nuevas ideas, y la reducción de costes por la vía de la deslocalización de la producción. De hecho, entre los países considerados en este trabajo, España destaca por presentar el porcentaje más alto de grandes empresas exportadoras con organización descentralizada, seguida de Reino Unido, Alemania y Austria ${ }^{45}$.

Bien es cierto que, en contraste con lo observado para ese selecto grupo de exportadores, el examen efectuado de diversos indicadores de buenas prácticas de dirección revela que en España predominan las empresas con baja calidad de gestión; es decir, aquellas en las que los objetivos no están bien definidos, su cumplimiento no está controlado, los esfuerzos de información sobre nuevas tecnologías son cortos, como también lo son los dedicados a conocer el mercado, a relacionarse con otros pares o con entidades técnicas, o a digitalizar los procesos productivos y de marketing (Yagüe Guillén y Campo Martínez, 2016). Todo ello, sumado al reducido tamaño medio, condiciona negativamente la productividad y, por consiguiente, la aptitud de nuestras empresas para competir en los mercados exteriores.

No obstante, parte del dinamismo mostrado por las exportaciones españolas en los años más recientes obedece al acrecentamiento de la base exportadora, claramente protagonizado por las firmas de inferior dimensión. Conforme a los datos del ICEX, entre 2010 y 2015, el número total de exportadoras aumentó en 38.015 (frente a un avance de solo 8.116 entre 2003 y 2008), de las cuales, apenas un 10 por 100 sobrepasó los 50.000 euros facturados, de lo que

${ }^{43}$ En realidad, el tamaño sería, según Huerta y Salas (2012), la consecuencia y no la causa de la calidad de la gestión interna, en la que inciden las dotaciones de capital humano, la formación y profesionalización de los directivos, el grado de delegación de autoridad y la cooperación entre capital y trabajo.

${ }^{44}$ La innovación organizativa y unas prácticas de gestión en las que se favorece la coordinación entre unidades operativas de forma más descentralizada son rasgos que distinguen a algunas de las mayores multinacionales españolas, como Zara, Viscofán, Indra o Acciona, que son líderes globales (Huerta Arribas y García Olaverri, 2014).

45 El estudio contempla una muestra de 14.000 empresas de siete países de la Unión Europea (Alemania, Francia, Reino Unido, Italia, Austria y España), comparando las estrategias organizativas del 10 por 100 de mayores exportadores de cada país, con especial atención al 1 por 100 que se sitúa a la cabeza (superstars), para el periodo 2000-2013. 
indica que se trata de empresas pequeñas ${ }^{46}$, con un valor medio por transacción reducido.

Pero más positivo todavía es que muchas de las empresas que han dado el salto al exterior durante la crisis se están consolidando como exportadoras regulares (definidas como aquellas que envían sus productos al exterior durante cuatro años consecutivos), y ello porque, además de ser estas empresas las que explican el crecimiento a largo plazo de las ventas exteriores, para que las nuevas relaciones comerciales contribuyan de forma significativa al crecimiento de las exportaciones es necesario que persistan (Besedeš y Prusa, 2011), puesto que ello extiende las posibilidades de aprovechar las economías de escala para acceder a nuevos destinos e intensificar el volumen de ventas en aquellos a los que ya exportan. Recurriendo de nuevo a los datos del ICEX, en la primera mitad de la década actual, las exportadoras regulares han pasado de 38.763 a 47.782 (un 43,5 por 100 más que en 2003). Una tendencia que se prolonga en los tres primeros trimestres de 2016, con un avance interanual del 1,3 por 100 en la cifra total de exportadoras y un adelanto aún más marcado (4,1 por 100) en el grupo de las que realizan esta actividad con carácter permanente.

- La creciente participación de las empresas españolas, tanto industriales como de servicios, en cadenas globales de producción, especialmente en las europeas, que ha otorgado una estabilidad mayor a sus ventas exteriores, amén de incidir positivamente sobre su productividad (Gandoy et al., 2016). Las firmas inmersas en redes internacionales son más grandes, más productivas, más innovadoras y poseen una mano de obra más cualificada. Es más, estas superiores características se mantienen respecto al resto de las empresas exportadoras (Gandoy, 2014). Por lo demás, este proceso de inclusión de España en las cadenas de valor internacionales se ha visto favorecido por las filiales extranjeras de gran tamaño presentes en nuestro país, que a su destacada vocación exportadora añaden la elevada intensidad de importación de bienes intermedios y finales.

\section{EXPORTACIONES: NECESARIO MOTOR DE LA RECUPERACIÓN Y EL CRECIMIENTO ECONÓMICO}

Pese a la fortaleza competitiva evidenciada por la economía española, a la que cabe otorgar una elevada calificación, la consolidación de su recuperación y el mantenimiento de un crecimiento económico sostenido, no sujeto a desequilibrios comerciales, necesariamente pasan, dado el actual contexto interno de elevado endeudamiento y restricciones presupuestarias que limitan la capacidad de la

${ }^{46}$ Aunque en todos los tramos de tamaño se ha incrementado durante la crisis el cupo de empresas que han buscado salida para su producción en los mercados foráneos, son las pymes las principales responsables del ascenso en la proporción de empresas exportadoras, tanto estables como no estables. Al respecto, consúltese Martín Machuca y Villanueva Cortés (2016). 
demanda interna para actuar como palanca del crecimiento, por la continuidad del avance en su proceso de internacionalización.

En la vertiente de la exportación, ello exige reforzar la competitividad de los productos españoles, lo que a su vez depende del aumento del valor exportado por productos, mercados de destino y empresas y, por supuesto, de la incorporación de nuevas firmas con nuevos artículos, es decir, del incremento del margen extensivo en la exportación.

La necesidad de una mayor diversificación de los bienes enviados al exterior, tanto en términos de variedad y complejidad, como de gamas de calidad, supone una importante oportunidad de negocio para las empresas que ya están internacionalizadas y también para aquellas que se están planteando salir al exterior. En este sentido, las actividades que cuentan con mayor potencial con vistas a diversificar nuestra cesta exportadora hacia productos con un mayor nivel de sofisticación y complejidad y, por ende, para estimular el crecimiento de la oferta exterior son maquinaria y equipo mecánico, productos químicos, instrumentos científicos y ópticos, productos metálicos, textil y confección y alimentos, bebidas y tabaco (Álvarez y Vega, 2016; Donoso y Martín, 2017), todos ellos identificados, salvo en lo que atañe a instrumentos científicos y ópticos, como sectores clave en la exportación española.

Asimismo, las empresas españolas disponen de un alto potencial para abordar otro de los desafíos pendientes, el de multiplicar los mercados a los que dirigen sus productos, acrecentando su todavía corta presencia en algunos de los más desarrollados y exigentes, casos de Estados Unidos y Canadá, así como en los más dinámicos, con China a la cabeza, país con el que, como se demuestra en el reciente trabajo de Gil-Pareja et al. (2016), existe un amplio margen para acrecentar las relaciones comerciales. Todo ello, claro está, sin descuidar las posiciones alcanzadas en los destinos de sólida implantación.

Otra de las tareas que han de acometerse cara a aumentar la intensidad exportadora de España, es la de sumar a esta actividad más empresas de elevada productividad, con mayores volúmenes de exportación y tasas de supervivencia. Un objetivo de envergadura que requiere de la eliminación de obstáculos a la competencia en los mercados, del incremento del tamaño empresarial y de la disminución de la protección a los pequeños establecimientos, así como de un apoyo más firme por parte de la política de promoción exterior.

Para traducir en logros los retos citados resulta imprescindible la mejora de la productividad, que durante la etapa de bonanza económica y hasta el inicio de la crisis ha crecido a un ritmo muy lento en España, alejándose del nivel medio anotado por los socios comunitarios más desarrollados. Como ya se ha señalado, el aumento de la productividad es un elemento esencial de la capacidad de las empresas para acometer los costes fijos y variables que la exportación impone y resistir las presiones competitivas. A la par, permite aminorar los costes laborales 
unitarios, y con ello los precios de los productos, y constituye la raíz del ascenso de los salarios y los beneficios sin que se eleven los precios, en definitiva, es el fundamento del progreso de la renta por habitante. Y dicha mejora de la productividad no podrá conseguirse sino es a través de la incorporación al proceso productivo de capital humano, base de una gestión de calidad en la empresa, y de capital tecnológico, fruto de la acumulación de inversiones en investigación e innovación. Estas son las piezas básicas del cambio en el modelo productivo que precisa la economía española y que desde luego debe ser impulsado desde las empresas, pero también ha de apostar por él el Estado, con políticas públicas más eficaces y mejor dotadas presupuestariamente (Myro et al., 2013; Myro, 2016).

\section{REFERENCIAS BIBLIOGRÁFICAS}

ALCALÁ, F. (dir.) (2013). Diferenciación vertical y sofisticación exportadora en el comercio internacional. Bilbao: Fundación BBVA.

ÁLVAREZ LÓPEZ, M. ${ }^{a}$ E. y FERNÁNDEZ-OTHEO, C. M. (2014). "El capital extranjero y la exportación española". En MYRO, R. (dir.): España en la inversión directa internacional (pp. 203-242). Madrid: Instituto de Estudios Económicos.

ÁLVAREZ LÓPEZ, M. ${ }^{a}$ E. y VEGA CRESPO, J. (2012). "El patrón exportador de la industria española: dificultades y logros recientes". Economistas, núm. 130, pp. 4862.

ÁLVAREZ LÓPEZ, M. ${ }^{a}$ E. y VEGA CRESPO, J. (2016). "La promoción exterior". En MYRO, R. (dir.): Una nueva política industrial para España (pp. 153-173). Madrid: Consejo Económico y Social.

ÁLVAREZ LÓPEZ, M. ${ }^{a}$ E.; MYRO, R. y VEGA CRESPO, J. (2016). "La inversión de las empresas españolas en el exterior: ¿Se reinicia la gran ola expansiva?". Papeles de Economía Española, núm. 150, pp. 2-19.

ALLARD, C.; CATALAN, M.; EVERAERT, L. y SGHERRI, S. (2005). "France, Germany, Italy, and Spain: Explaining Differences in External Sector Performance Among Large Euro Area Countries", IMF Country Report 05/401, International Monetary Fund.

ANTRÀS, P. (2010). "La nueva teoría del comercio internacional y el comportamiento de las exportaciones españolas". Blog Nada es Gratis, FEDEA, 01 de enero de 2010.

BAJO-RUBIO, Ó.; BERKE, B. y ESTEVE, V. (2016). "The effects of competitiveness on trade balance: The case of Southern Europe". Economics Discussion Paper 2016-30, Kiel Institute for the World Economy.

BANCO DE ESPAÑA (2011). Informe Anual 2011, Madrid.

BARBA-NAVARETTI, G.; BUGAMELLI, M.; SCHIVARDI, F.; ALTOMONTE, C.; HORGOS, D. y MAGGIONI, D. (2011). "The global operations of European firms. The second EFIGE policy report". Bruegel Blueprint Series, vol. XII, Bruselas.

BBVA (2016). Situación EAGLEs. Informe Anual 2016, BBVA Research (https://www.bbvaresearch.com/publicaciones/situacion-eagles-informe-anual-2016/) 
BEHRENS, K. y OTTAVIANO, G. (2011). "General Equilibrium Trade Theory and Firm Behaviour". En BERNHOFEN, D.; FALVEY, R.; GREENAWAY, D. Y KREICKEMEIER, U. (eds.): Palgrave Handbook of International Economics (pp. 119-159). Basingstoke: Palgrave MacMillan.

BELKE, A.; OEKING, A. y SETZER R. (2014). "Exports and capacity constraints-A smooth transition regression model for six euro area countries". Working Paper Series 1740, European Central Bank.

BELKE, A.; OEKING, A. y SETZER R. (2015). "Domestic demand, capacity constraints and export dynamics: Empirical evidence for vulnerable euro area countries". Economic Modelling, vol. 48, pp. 315-325.

BENKOVSKIS, K. y WOERZ, J. (2015). Cost competitiveness: A dangerous obsession, VOX CEPR's Policy Portal, 24 de febrero de 2015.

BERNARD, A. B.; JENSEN, J. B.; REDDING, S. J. y SCHOTT, P. K. (2012). "The Empirics of Firm Heterogeneity and International Trade". Annual Review of Economics, vol. 4, núm. 1, pp. 283-313.

BESEDEŠ, T., y PRUSA, T. J. (2011). "The role of extensive and intensive margins and export growth". Journal of Development Economics, vol. 96, núm. 2, pp. 371-379.

BREUER, S. y KLOSE, J. (2015). "Who Gains From Nominal Devaluation? An Empirical Assessment of Euro-area Exports and Imports". The World Economy, vol. 38, núm. 12, pp. 1966-1989.

CANALS, C. y FERNÁNDEZ, E. (2008). "Luces y sombras de la competitividad exterior de España". Documentos de Economía "la Caixa" 10, Servicio de Estudios de "la Caixa".

CORREA-LÓPEZ, M. y DOMÉNECH, R. (2012). "La Internacionalización de las Empresas Españolas". Documentos de Trabajo 12/29, BBVA Research.

COSTA, M. ${ }^{a}$ T.; FERNÁNDEZ-OTHEO, C. M. y VEGA, J. (2015). "La empresa y su internacionalización". En GARCÍA DELGADO, J. L. y MYRO, R. (dirs.): Economía española. Una introducción, segunda edición (pp. 111-129). Navarra: Aranzadi.

CRESPO RODRíguEZ, A.; PÉREZ-QUIRÓS, G. y SEGURA-CAYUELA, R. (2011). "Indicadores de competitividad: la importancia de la asignación eficiente de recursos". Boletín Económico, diciembre, Banco de España, Madrid, pp. 31-39.

CUADRADO ROURA, J. R. (2015). Exportaciones españolas de servicios. Evolución, retos y perspectivas. Madrid: Instituto de Estudios Económicos.

DE LUCIO, J.; MíNGUEZ, R.; MINONDO, A. y REQUENA, F. (2011). "The extensive and intensive margins of Spanish trade". International Review of Applied Economics, vol. 25, núm. 5, pp. 1-17.

DE LUCIO, J.; MÍNGUEZ, R.; MINONDO, A. y REQUENA, F. (2017). "Los márgenes del crecimiento de las exportaciones españolas antes y después de la Gran Recesión". Estudios de Economía Aplicada, núm. 35-1.

DOMÉNECH, R. (2009). "Competitividad". En La crisis económica española en un contexto global (pp. 78-102). Fundación Alternativas e Instituto Universitario de Análisis Económico y Social, Seminarios y Jornadas 60/2009.

DONOSO, V. y MARTíN, M. (2017). "Complejidad económica y densidad productiva como fuentes de competitividad". Estudios de Economía Aplicada, núm. 35-1.

EASTERLY, W.; RESHEF, A. y SCHWENKENBERG, J. (2009). "The power of exports". Policy Research Working Paper 5081, The World Bank. 
EPPINGER, P. S.; MEYTHALER, N.; SINDLINGER, M. y SMOLKA, M. (2015). "The Great Trade Collapse and the Spanish Export Miracle: Firm-level Evidence from the Crisis". Economics Working Papers 2015-10, Aarhus University.

ESTEVE, S. y RODRÍGUEZ, D. (2014). "Efectos de la inversión exterior sobre la exportación, el capital humano y el esfuerzo tecnológico". En MYRO, R. (dir.): España en la inversión directa internacional (pp. 331-354). Madrid: Instituto de Estudios Económicos.

ESTEVES, P. S. y PRADES, E. (2016). "On domestic demand and export performance in the euro area countries: does export concentration matter?". Working Paper Series 1909, European Central Bank.

ESTRADA, Á.; JIMENO, J. F. y MALO DE MOLINA, J. L. (2009). "La economía española en la UEM: Ios diez primeros años". Documentos Ocasionales, núm. 0901, Banco de España, Madrid.

EUROPEAN COMMISSION (2000). European Competitiveness Report, Luxembourg: Publications Office of the European Union.

FREUND, C. y PIEROLA, M. D. (2013). "Export Superstars". Policy Research Working Paper 6222, The World Bank.

FUENTES CASTRO, D. (2016). "Exportaciones españolas de bienes y servicios. No solo es el turismo". Cuadernos de Información Económica, Economía y Finanzas Españolas, núm. 255, noviembre/diciembre, pp. 35-46.

GANDOY, R. (2014). "La implicación española en cadenas globales de producción". En ALONSO, J. A. y MYRO, R. (dirs.): Ensayos sobre Economía Española. Homenaje a José Luis García Delgado (pp. 213-224). Navarra: Aranzadi.

GANDOY, R. y ÁLVAREZ, M. ${ }^{a}$ E. (2015). "El sector industrial". En GARCÍA DELGADO, J. L. y MYRO, R. (dirs.): Lecciones de Economía española, duodécima edición (pp. 163-180). Navarra: Aranzadi.

GANDOY, R.; DÍAZ MORA, C.; CÓRCOLES GONZÁLEZ, D. y GONZÁLEZ DÍAZ, B. (2016). "Inserción en las cadenas de valor internacionales". En MYRO, R. (dir.): Una nueva política industrial para España (pp. 133-151). Madrid: Consejo Económico y Social.

GIL-PAREJA, S.; LLORCA-VIVERO, R. y PANIAGUA-SORIANO, J. (2016). "EI potencial de China". Papeles de Economía Española, núm. 150, pp. 38-50.

GIORDANO, C. y ZOLLINO, F. (2015). "Exploring price and non-price determinants of trade flows in the largest euro-area countries". Working Paper Series 1789, European Central Bank.

GOLDMAN SACHS (2011). "Eurozone Competitiveness: Beyond Costs". European Weekly Analyst 11/02, January 13.

GÓMEZ LOSCOS, A. y MARTÍN MACHUCA, C. (2014). "Una comparación de la respuesta del sector exterior en las dos últimas recesiones". Boletín Económico, mayo, Banco de España, Madrid, pp. 43-52.

GORDO, E. (2007). "La competitividad internacional de España en un contexto global". Economistas, núm. 114, pp. 26-36.

GORDO y TELLO, P. (2011). "Diversificación, precios y calidad de las exportaciones españolas: una comparación a nivel europeo". Cuadernos Económicos de ICE, núm. 82, pp. 31-61.

GROS, D. (2016a). "Is this the end of globalization?", World Economic Forum (https://www.weforum.org/agenda/2016/03/is-this-the-end-of-globalization). 
GROS, D. (2016b). "Adjustment within the Euro Area: Is it all about competitiveness?". CEPS Special Report 127, Centre for European Policy Studies, Brussels.

GUILLÉN, M. F. y GARCÍA CANAL, E. (2011). Las nuevas multinacionales: las empresas españolas en el mundo. Barcelona: Ariel.

HAUSMANN, R.; HWANG, J. y RODRIK, D. (2007). "What you export matters". Journal of Economic Growth, vol. 12, núm. 1, pp. 1-25.

HIDALGO, C. A. y HAUSMANN, R. (2009). "The building blocks of economic complexity". PNAS, vol. 106, núm. 26, pp. 10570-10575.

HUERTA ARRIBAS, E. y GARCÍA OLAVERRI, M. C. (2014). "La capacidad de dirección en las empresas españolas y el debate de la productividad". En FARIÑAS GARCÍA, J. C. y FERNÁNDEZ DE GUEVARA, J. (eds.): La empresa española ante la crisis del modelo productivo: productividad, competitividad e innovación (pp. 129-162). Bilbao: Fundación BBVA.

JÄÄSKELÄ, J. y MATHEWS, T. (2015). "Explaining the Slowdown in Global Trade". Reserve Bank of Australia Bulletin, pp. 39-46.

JIMÉNEZ, N. y MARTíN, E. (2010). "Un análisis de la cuota de mercado de la UEM en el período 1994-2007". Boletín Económico, enero, Banco de España, Madrid, pp. 123136.

JOHANSON, J. y VAHLNE, J. E. (1977). "The Internationalization Process of the Firm: A Model of Knowledge Development and Increasing Foreign Market Commitment". Journal of International Business Studies, vol. 8, núm. 1, pp 23-32.

JOHANSON, J. y WIEDERSHEIM-PAUL, F. (1975). "The internationalization of the firm. Four Swedish cases". Journal of Management Studies, vol. 12, pp. 305-323.

KALDOR, N. (1978). "The effect of devaluations on trade in manufactures". En KALDOR, N. (ed.): Further Essays on Applied Economics (pp. 99-118). London: Duckworth.

MÁÑEZ, J. A.; REQUENA, F.; ROCHINA-BARRACHINA, M. E. y SANCHIS-LLOPIS, J. A. (2011). "El papel de los márgenes extensivo e intensivo en el crecimiento de las exportaciones manufactureras españolas por sectores tecnológicos". Cuadernos Económicos de ICE, núm. 82, pp. 63-83.

MARIN, D.; SCHYMIK, J. y TSCHEKE, J. (2015). "Europe's export superstars. It's the organisation!". Bruegel Working Paper 2015/05.

MARTíN, C. (2011). "Un análisis del destino geográfico de las exportaciones españolas de bienes a través de una ecuación de gravedad". Boletín Económico, Banco de España, julio-agosto, pp. 97-105.

MARTÍN, C. (2016). "Evolución macroeconómica de la retribución de los trabajadores durante la crisis y su incidencia en los organismos autónomos de solución de conflictos". Jornada sobre Los salarios durante la crisis económica y su incidencia en el ASAC y los sistemas de solución de conflictos, Consejo Económico y Social, Madrid, 16 de noviembre de 2016.

MARTíN, C. y TELLO, P. (2013). "La actividad exportadora y la competitividad-no precio de las empresas europeas". Boletín Económico, mayo, Banco de España, Madrid, pp. 41-51.

MARTÍN MACHUCA, C. y VILLANUEVA CORTÉS, P. (2016). "El papel de las exportaciones en la recuperación actual de la economía española". Economistas, núm. 148, pp. 23-47. 
MARTÍNEZ-MONGAY, C. y MAZA SIERRA, L. A. (2009). "Competitiveness and growth in EMU: The role of the external sector in the adjustment of the Spanish economy". European Economy, Economic Papers, Brussels, núm. 355.

MELITZ, M. J. (2003). "The impact of trade on intra-industry reallocations and aggregate industry productivity". Econometrica, vol. 71, núm. 6, pp. 1695-1725.

MELITZ, M. J. y REDDING, S. J. (2014). "Heterogeneous firms and trade". En GOPINATH, G; HELPMAN, E. y ROGOFF, K. (eds.): Handbook of International economics (vol. 4, pp. 1-54). Amsterdam: Elsevier.

MERINO DE LUCAS, F. (2012). "Firms' internationalization and productivity growth". Research in Economics, vol. 66, núm. 4, pp. 349-354.

MINONDO, A. (2012). "Trading firms in the Spanish services sector". MPRA Paper 43224, University Library of Munich, Germany.

MYRO, R. (2009). "El puzle de la productividad y la competitividad". El País, 5 de julio.

MYRO, R. (2014a). "Paradoja de la productividad y la competitividad". En ALONSO, J. A. y MYRO, R. (dirs.): Ensayos sobre Economía Española. Homenaje a José Luis García Delgado (pp. 97-108). Navarra: Aranzadi.

MYRO, R. (dir.) (2014b). España en la inversión directa internacional. Madrid: Instituto de Estudios Económicos.

MYRO, R. (2015a). España en la economía global. Claves del éxito de las exportaciones españolas. Barcelona: RBA.

MYRO, R. (2015b). "Competitividad, productividad y nuevo modelo productivo". Información Comercial Española, núm. 883, pp.145-160.

MYRO, R. (dir.) (2016). Una nueva política industrial para España. Madrid: Consejo Económico y Social.

MYRO, R. y ÁLVAREZ LÓPEZ, M. ${ }^{a}$ E. (2010). "El imperativo de la competitividad para la economía española". Claves de la Economía Mundial, ICEX-ICEI, pp. 155-162.

MYRO, R. y FERNÁNDEZ-OTHEO, C. M. (2008). "Deslocalización de empresas e inversión extranjera directa en la industria española". Papeles de Economía Española, núm. 116, pp. 184-202.

MYRO, R. (dir.); ÁLVAREZ LÓPEZ, M. ${ }^{a}$ E.; FERNÁNDEZ-OTHEO, C. M.; RODRÍGUEZ RODRÍGUEZ, D. y VEGA CRESPO, J. (2013). Fortalezas competitivas y sectores clave en la exportación española. Madrid: Instituto de Estudios Económicos.

OMC (2016). Estadísticas de corto plazo sobre el comercio (https://www.wto.org/english/ res_e/statis_e/daily_update_e/quarterly_trade_e.xls).

PELTONEN, A; SKALA, M.; SANTOS, M. y PULA, G. (2008). "Imports and profitability in the euro area manufacturing sector. The role of emerging market economies". Working Paper Series 918, European Central Bank.

PEÑA PEÑA, J. (2016). "Las exportaciones españolas de servicios: mitos y realidades". Economistas, núm. 148, pp. 49-65.

PÉREZ F. (dir.) (2004). La competitividad de la economía española: inflación, productividad y especialización. Barcelona: Servicio de Estudios de "la Caixa". Colección Estudios Económicos, núm. 32.

PRADES, E. y GARCÍA, C. (2015). "Actualización de la función de las exportaciones españolas de bienes". Boletín Económico, abril, Banco de España, pp. 31-39.

RICHARDSON, J. D. (1971). "Constant-market-shares analysis of export growth". Journal of International Economics, vol. 1, núm. 2, pp. 227-239. 
VEGA CRESPO, J. y ÁlVAREZ LÓPEZ, M. ${ }^{a}$ E. (2011). "Estrategias de competitividad exterior de la economía española". Principios, Estudios de Economía Política, núm.18, pp. 31-46.

WAGNER, J. (2016). "A survey of empirical studies using transaction level data on exports and imports". Review of World Economics, vol. 152, núm. 1, pp. 215-225.

YAGÜE GUILLÉN, M. ${ }^{a}$ J. y CAMPO MARTÍNEZ, S. (2016). "La formación de capital humano y de capital directivo". En MYRO, R. (dir.): Una nueva política industrial para España (pp. 99-114). Madrid: Consejo Económico y Social. 
